\title{
Norepinephrine Modulates Coding of Complex Vocalizations in the Songbird Auditory Cortex Independent of Local Neuroestrogen Synthesis
}

\author{
Maaya Z. Ikeda, ${ }^{1,3}$ Sung David Jeon, ${ }^{3}$ Rosemary A. Cowell, ${ }^{2}$ and Luke Remage-Healey ${ }^{1,2,3}$ \\ ${ }^{1}$ Molecular and Cellular Biology Program, ${ }^{2}$ Neuroscience and Behavior Program, and ${ }^{3}$ Center for Neuroendocrine Studies, University of Massachusetts, \\ Amherst, Massachusetts 01003
}

\begin{abstract}
The catecholamine norepinephrine plays a significant role in auditory processing. Most studies to date have examined the effects of norepinephrine on the neuronal response to relatively simple stimuli, such as tones and calls. It is less clear how norepinephrine shapes the detection of complex syntactical sounds, as well as the coding properties of sensory neurons. Songbirds provide an opportunity to understand how auditory neurons encode complex, learned vocalizations, and the potential role of norepinephrine in modulating the neuronal computations for acoustic communication. Here, we infused norepinephrine into the zebra finch auditory cortex and performed extracellular recordings to study the modulation of song representations in single neurons. Consistent with its proposed role in enhancing signal detection, norepinephrine decreased spontaneous activity and firing during stimuli, yet it significantly enhanced the auditory signal-to-noise ratio. These effects were all mimicked by clonidine, an $\alpha-2$ receptor agonist. Moreover, a pattern classifier analysis indicated that norepinephrine enhanced the ability of single neurons to accurately encode complex auditory stimuli. Because neuroestrogens are also known to enhance auditory processing in the songbird brain, we tested the hypothesis that norepinephrine actions depend on local estrogen synthesis. Neither norepinephrine nor adrenergic receptor antagonist infusion into the auditory cortex had detectable effects on local estradiol levels. Moreover, pretreatment with fadrozole, a specific aromatase inhibitor, did not block norepinephrine's neuromodulatory effects. Together, these findings indicate that norepinephrine enhances signal detection and information encoding for complex auditory stimuli by suppressing spontaneous "noise" activity and that these actions are independent of local neuroestrogen synthesis.
\end{abstract}

Key words: birdsong; locus coeruleus; neurosteroid; 17-beta-estradiol; noradrenaline; pattern classification

\section{Introduction}

Neuromodulators are critical for state-dependent changes in neural circuit activity and behavior. Norepinephrine in particular is important for both altering the gain of sensory stimuli and for fast behavioral switching (Bouret and Sara, 2005). During development, sensory plasticity of the visual and auditory cortex is dependent on norepinephrine, indicating a key role in shaping early sensory experience (Kasamatsu et al., 1979; Edeline et al., 2011; Shepard et al., 2015). Computational models and in vitro recordings have generated predictions about the role of norepi-

\footnotetext{
Received Oct. 27, 2014; revised April 13, 2015; accepted May 11, 2015.

Author contributions: M.Z.I., R.A.C., and L.R.-H. designed research; M.Z.I., S.D.J., and R.A.C. performed research; M.Z.I., S.D.J., R.A.C., and L.R.-H. analyzed data; M.Z.I. and L.R.-H. wrote the paper.

This work was supported by National Institute of Neurological Disorders and Stroke R00NS066179 and R01NS082179. We thank Thomas Cao, Michael Stefanelli, Rachel Xue, Laura Bernal-Corzo, Andrew Chao, Ashley Paon, Joseph Starrett, Garrett Scarpa, Amanda Krentzel, Daniel Vahaba, and Ifeyinwa Arinze for technical assistance with this project; Jon Sakata for audio recordings of Bengalese finch song; and Colin Saldanha for generous donation of the aromatase antibody.

The authors declare no competing financial interests.

Correspondence should be addressed to Dr. Luke Remage-Healey, Department of Psychological and Brain Sciences, Center for Neuroendocrine Studies, University of Massachusetts, Amherst, MA 01003. E-mail: healey@cns.umass.edu.

DOI:10.1523/JNEUROSCI.4445-14.2015

Copyright $\odot 2015$ the authors $\quad 0270-6474 / 15 / 359356-13 \$ 15.00 / 0$
}

nephrine in shaping neural circuit activity, via specific actions at adrenergic receptor (AR) subclasses (Hasselmo et al., 1997; Carey and Regehr, 2009). In mammalian auditory cortex, norepinephrine enhances auditory processing of pure tones and calls, by decreasing spontaneous and auditory-evoked firing, altering excitatory/inhibitory balance, and altering frequency tuning (Foote et al., 1975; Manunta and Edeline, 1997, 2004; Salgado et al., 2011a, 2012). However, it is less clear what role norepinephrine plays in the coding of complex sensory stimuli; that is, beyond the processing of simple stimuli, such as tones and the tuning of receptive fields (Hurley et al., 2004).

Songbirds have become a premiere system for understanding how auditory neurons encode complex, learned vocalizations (Woolley and Rubel, 2002; Elie and Theunissen, 2015). Norepinephrine has been associated with auditory processing in the songbird brain (Sockman and Salvante, 2008; Castelino and Schmidt, 2010), and norepinephrine can influence the activity of songbird premotor neurons via actions at $\alpha$-ARs (Cardin and Schmidt, 2004; Sizemore and Perkel, 2008). Noradrenergic signaling is necessary for immediate-early gene induction in response to song, as well as long-term adaptation of forebrain neurons to familiar stimuli (Lynch et al., 2012; Velho et al., 2012). Songbirds therefore provide an excep- 
tional opportunity to test how norepinephrine modulates the neural coding of auditory stimuli, in particular the coding of complex vocalizations important for social communication and learning.

Norepinephrine likely interacts with other neuromodulators in the control of audition. In one forebrain region of songbirds, the caudomedial nidopallium (NCM), a region analogous to mammalian secondary auditory cortex, local estradiol levels are elevated in response to hearing songs (Remage-Healey et al., 2008 , 2012). In the canary NCM, fibers expressing tyrosine hydroxylase surround aromatase-positive neurons, suggesting that catecholamines regulate local estradiol synthesis (Appeltants et al., 2004). Furthermore, inhibiting either catecholamine or estradiol actions in the NCM disrupts auditory processing and immediate-early gene induction (Lynch and Ball, 2008; RemageHealey et al., 2010; Poirier and Van der Linden, 2011; Velho et al., 2012; Vahaba et al., 2013). These studies suggest that catecholamines and neuroestrogens interact to modulate auditory processing in songbirds, although this interaction has not been tested in any system to date.

Here, we directly test the hypothesis that norepinephrine regulates the auditory coding of complex vocalizations in the songbird forebrain. Furthermore, we examine whether norepinephrine actions are dependent on local estradiol synthesis. We find that norepinephrine enhances the coding accuracy of higher auditory cortical neurons for complex vocalizations, an effect similar to neuroestrogen modulation, but without directly impacting neuroestrogen synthesis.

\section{Materials and Methods}

A total of 74 female zebra finches were used in this study. The protocols for animal care and use were approved by the Institutional Animal Care and Use Committee at the University of Massachusetts (Amherst, Massachusetts). Adult female zebra finches were housed in unisex cages under photoperiod of $14 \mathrm{~h}$ light (7:00-21:00) and $10 \mathrm{~h}$ dark. We elected to perform these experiments in females because of the more extensive prior literature on catecholamines in the auditory forebrain of female songbirds (Sockman and Salvante, 2008; Matragrano et al., 2011, 2012; Pawlisch et al., 2011). In vivo microdialysis procedures closely followed those as detailed in a recent protocol paper (Ikeda et al., 2014).

Surgery. The protocol for surgeries were adapted from Remage-Healey et al. $(2008,2010)$ and Remage-Healey and Joshi (2012) and Ikeda et al. (2014). Birds were orally administered meloxicam ( $1 \mu \mathrm{l} / \mathrm{g}$ weight). After $20 \mathrm{~min}$, birds were intramuscularly injected with $45 \mu \mathrm{l}$ of equithesin. Lidocane ( $20 \mu \mathrm{l}, 4 \%$ in ethanol; Sigma-Aldrich) was then injected subcutaneously under the scalp for local anesthesia, and an incision was made to remove the skin to expose the skull. The bifurcation point of the midsagittal sinus was used as point of origin. Using a stereotaxic frame with a micromanipulator, the coordinates for cannula insertion and recording site were located.

For microdialysis experiments, a guide cannula with a dummy probe (CMA 7; CMA Microdialysis AB) was inserted into the brain $(1.1 \mathrm{~mm}$ lateral and $1.2 \mathrm{~mm}$ rostral relative to the point of origin). The tip of the cannula was placed $1.4 \mathrm{~mm}$ ventral from the surface of the brain. The cannula was fixed to the skull with dental cement and cyanoacrylate. The birds were allowed to recover for at least $4 \mathrm{~d}$ following surgery before microdialysis began.

Retrodialysis. The day before starting experiments, the dummy probe was replaced with a microdialysis probe (CMA 7 with $2 \mathrm{~mm}$ membrane; Microdialysis Probe, CMA Microdialysis) prefilled with aCSF. The inlet and outlet tubing from the probe was connected to a microdialysis swivel (Instech Laboratories) and then to a syringe pump (PHD 2000 Harvard Apparatus) and a collection tube, respectively, with FEP tubing $(0.12 \mathrm{~mm}$ inner diameter; CMA Microdialysis) (see Fig. 3A). Animals were placed inside a sound-attenuation chamber with a one-way glass partition (Eckel Industries) to allow undisturbed sample collection and manipu- lation of retrodialysis conditions. The probe was perfused at a flow rate of $0.5 \mu \mathrm{l} / \mathrm{min}$ with aCSF (199 mm NaCl, $26.2 \mathrm{~mm} \mathrm{NaHCO}_{3}, 2.5 \mathrm{~mm} \mathrm{KCl}, 1$ $\mathrm{mm} \mathrm{NaH}_{2} \mathrm{PO}_{4}, 1.3 \mathrm{~mm} \mathrm{MgSO}_{4}, 2.5 \mathrm{~mm} \mathrm{CaCl}, 11 \mathrm{~mm}$ glucose, $1 \% \mathrm{BSA}, \mathrm{pH}$ 7.4-7.6). Twenty-four hours after probe implantation, the flow rate was increased to $2 \mu \mathrm{l} / \mathrm{min}$ at least $30 \mathrm{~min}$ before the start of the experiment and kept at this rate until the end of the experiment.

Each experiment consisted of collecting consecutive samples twice before (Pre1 and Pre2), once during (Retro), and twice after (Post1 and Post2) retrodialysis treatments. All collection intervals were $30 \mathrm{~min}$. Regular aCSF was pumped through the probe during the pre and post periods, while $0,0.01$, or $0.1 \mathrm{~mm}$ of norepinephrine-hydrocloride (Sigma-Aldrich) aCSF solution was infused through the dialysis probe during retrodialysis (Retro). Experiments were conducted twice a day in the morning (9:30 A.M.) and the afternoon (2:00 P.M.) for 3-4 d with treatments randomized for each subject and period. The animals were monitored with a video camera during retrodialysis. In a subset of animals, experiments were performed at night to test for potential circadian effects of norepinephrine on estradiol levels in NCM. The night experiments began at 9:30 P.M. relative time (i.e., $30 \mathrm{~min}$ after lights off). Estradiol concentrations in the dialysate samples were measured by ELISA, previously validated with GC/MS (Remage-Healey et al., 2008, 2012). All samples from each animal were assayed in the same run to minimize interassay variation. For adrenergic antagonist retrodialysis (reagents purchased from Sigma-Aldrich), samples were collected in the same manner as norepinephrine retrodialysis, but only two samples were collected (once before and once during antagonist treatment with $30 \mathrm{~min}$ collection intervals) because we did not observe a difference between the two pre collection periods in the previous retrodialysis experiment.

The videotaped trials were analyzed offline using JWatcher to assess whether there were any changes in locomotor activity with treatment. Within $2 \mathrm{~d}$ after the last experiment, birds were killed using an overdose of isoflurane. They were then either rapidly decapitated or transcardially perfused with $0.1 \mathrm{M}$ PBS followed by $10 \%$ formalin. The brains were extracted and fixed in $20 \%$ sucrose formalin solution for at least $24 \mathrm{~h}$ at $4^{\circ} \mathrm{C}$. The brains were then frozen and embedded in OCT at $-80^{\circ} \mathrm{C}$, sectioned by cryostat $(45 \mu \mathrm{m})$, and Nissl stained with thionin to confirm the location of the probe site. All microdialysis experiments below are from birds confirmed to have probe sites restricted to NCM.

Electrophysiology with retrodialysis. For electrophysiology experiments, the skull dorsal to the NCM was marked with a \#11 scalpel blade. Using cyanoacrylate and dental acrylic, a custom-made head post was attached to the rostral skull. A silver wire reference ground was inserted under the upper-leaflet of skull. Experiments were conducted 1-2 d after surgery. On the day of the experiment, the bird was anesthetized with three $30 \mu \mathrm{l}$ intramuscular injections of $20 \%$ urethane spaced $30 \mathrm{~min}$ apart. After the last injection, the bird was secured by the head post to an in vivo recording rig inside a sound attenuation booth (Industrial Acoustics). Body temperature was maintained at $\sim 37^{\circ} \mathrm{C}$ with a heating pad (FHC Neurocraft). A small craniotomy exposed the brain surface dorsal to NCM. A microdialysis probe (as above, filled with aCSF as above) and an extracellular electrode (Carbostar-1, Kation Scientific) were inserted into the $\mathrm{NCM}(\sim 1.4 \mathrm{~mm}$ ventral from the surface of the brain) adjacent to each other (within $200-500 \mu \mathrm{m}$ ). All recordings began after a minimum 20 min delay following implantation of the probe/electrode to allow implantation-induced changes to subside. Each recording session collected NCM extracellular responses to randomized 20 repetitions of four $2 \mathrm{~s}$ playback stimuli (CON1, conspecific zebra finch song 1; CON2, conspecific zebra finch song 2 ; HET, heterospecific bengalese finch song; $\mathrm{WN}$, white noise; $\approx 70 \mathrm{~dB}$ ). The interstimulus interval was at $10 \mathrm{~s}$, and the total duration of each recording was $\sim 15 \mathrm{~min}$. All recordings were amplified, bandpass filtered $(300-5000 \mathrm{~Hz}$; A-M Systems), and digitized at $20 \mathrm{kHz}$ (Micro 1401, Spike 2 software; Cambridge Electronic Design).

To collect baseline responses to auditory stimuli, the first recording was collected following $30 \mathrm{~min}$ of aCSF perfusion (Pre). To test the effect of norepinephrine $(N=17)$, recordings were conducted after 30-40 min infusion of $0.1 \mathrm{~mm}$ norepinephrine (in aCSF, NE), and then followed by 30 min aCSF washout (Post). In a separate set of birds $(N=10)$, to test the effect of norepinephrine in the presence an aromatase inhibitor, fadrozole (100-500 $\mu \mathrm{M}$ ) (Wade et al., 1994), the NCM was perfused with 
fadrozole for 30-50 min, before and during and after $0.1 \mathrm{~mm}$ norepinephrine infusions. In a separate set of animals $(N=9)$, the effect of adrenergic agonists (all from Sigma-Aldrich), cirazoline $(N=2)$, and clonidine $(N=6)$, and an $\alpha 2$ antagonist, idazoxan $(N=1)$, were tested at two different concentrations ( $0.5 \mathrm{~mm}$, LOW; $5 \mathrm{~mm}$, HIGH). After the "Pre" recording, the sites were infused with low dose of the agonists, and then with high dose. For the agonist experiments, we noticed that some single units $(N=6$ of 13$)$ were not auditory for some stimuli at baseline (evoked firing - spontaneous firing $<0$ ), but following agonist treatment they developed an auditory response pattern (evoked firing spontaneous firing $>0$ ), and these units were included in the analyses. Each infusion period was followed by recording sessions. For all experiments, recording sites were lesioned (10 $\mu \mathrm{A}$ for $10 \mathrm{~s})$ to allow electrode site confirmation.

The dialysates during the infusions and recordings were collected and stored at $-80^{\circ} \mathrm{C}$ and were later measured for estradiol levels with ELISA. Immediately after the electrophysiological recordings, animals were killed in the same way as the microdialysis experiment. The brains were extracted for anatomical confirmation of electrode and probe sites.

Double-label immunocytochemistry. A separate set of $n=2$ animals were killed with an overdose of isoflurane and transcardially perfused with $0.1 \mathrm{M}$ PBS followed by fresh ice-cold $4 \%$ PFA. Brains were extracted and postfixed in $4 \%$ PFA for $1 \mathrm{~h}$. The brains were then cryoprotected in $30 \%$ sucrose PBS overnight. The brains were embedded in OCT and cryosectioned at $40 \mu \mathrm{m}$ into $0.1 \mathrm{M} \mathrm{PB}$. The free-floating sections were rinsed with $\mathrm{PB}$ and blocked and permeabilized with $10 \%$ normal goat serum in $0.3 \%$ PBS and Triton X-100 (PBT) for $1 \mathrm{~h}$. The sections were incubated with anti-zebra finch aromatase rabbit antibody (1:2500 in $0.3 \%$ PBT; generous gift of Dr. Colin Saldanha) in room temperature for $1 \mathrm{~h}$ and in $4^{\circ} \mathrm{C}$ for $48 \mathrm{~h}$. The sections were then washed with $0.1 \%$ PBT, incubated with goat anti-rabbit IgG (1:500 in 0.3\% PBT; Vector Laboratories; $1 \mathrm{~h}$ ), washed in $0.1 \%$ PBT, treated with avidin-biotin-peroxidase complex (Vectastain ABC Kit, Vector Laboratories; 90 min), washed again in $0.1 \%$ PBT, and developed in Vector NovaRED enzyme substrate (Vector Laboratories; 5-10 min). The sections were stained for DBH by repeating the procedure using anti-DBH rabbit (1:8000; Immunostar), goat anti-rabbit IgG (1:500; Vector Laboratories), and Vector SG enzyme substrate (Vector Laboratories; 5-10 min). After development, the sections were mounted onto gelatin-coated slides. The slides were dried overnight and coverslipped with Permount (Fisher Scientific) and visualized under a light microscope (Zeiss).

Because the two primary antibodies were raised in the same species (rabbit), the immunostaining was analyzed with caution. However, generally, the two populations were clearly distinguishable from one another, as DBH was found in beaded fibers and aromatase was found in cell bodies and their processes. Sections exposed to both primary antibodies were compared with sections from the same animals in the same run exposed to one or the other primary antibody to assess reliability.

Data analysis. For dialysate samples, to normalize individual variability in levels of estradiol in the baseline samples $(0.1-10 \mathrm{pg} / \mathrm{ml})$, the raw data for collections Pre2, Retro, Post1, and Post2 were transformed according to the following formula:

$$
(\text { Raw pg/ml }+1 \mathrm{pg} / \mathrm{ml}) /(\operatorname{Pre} 1 \mathrm{pg} / \mathrm{ml}+1 \mathrm{pg} / \mathrm{ml})
$$

The effect of norepinephrine on the normalized estradiol levels across treatments was then tested using nonparametric Friedman ANOVA.

Electrophysiological recordings were analyzed using Spike2 (Cambridge Electronic Design). Baseline activity and stimulus-evoked activity were obtained from recordings $2 \mathrm{~s}$ before (baseline) and $2 \mathrm{~s}$ after (during stimuli) the beginning of the stimuli.

For multiunit activity, a threshold for each recording session was set such that spiking activity exceeded background noise by 1.5 - to 3 -fold. For each recording session, the threshold level was maintained for the entire set of recordings, so that all sampling periods per experiment (Pre, NE, Post) were analyzed with the same threshold (as in Remage-Healey and Joshi, 2012). The number of action potentials with amplitudes above threshold was counted for each $10 \mathrm{~ms}$ interval (bin). Multiunit activity was analyzed to determine overall patterns (see, e.g., Fig. 1C); all results reported below are for sorted single units.

To determine whether norepinephrine induced changes in NCM auditory-evoked activity at the level of single neurons, recordings were sorted for single-unit analysis (as in Remage-Healey et al., 2010; RemageHealey and Joshi, 2012). Large-amplitude single units were identified via waveform sorting using principal component analysis (see Fig. 1B). Spikes with defined waveforms were matched to a sorting template with an accuracy range of $60 \%-100 \%$, and the spike $z$-score values were calculated for each identified single unit. Playback peristimulus time histograms were generated for each single unit to verify auditory responsiveness. Only units with refractory periods longer than $1 \mathrm{~ms}$ were included in the analysis. The normalized auditory response ("auditory $z$-score") values were calculated by taking the difference between the mean number of spikes per bin during the stimulus ( $2 \mathrm{~s}$ from the onset) and the mean number of spikes per bin during the baseline period $(2 \mathrm{~s}$ before stimulus onset) divided by the SD of the difference between the stimulus and baseline periods (Remage-Healey and Joshi, 2012). Bursts were defined as a series of three or more spikes with interspike interval $<$ $10 \mathrm{mS}$. The signal-to-noise ratio was also computed by calculating the ratio between the number of spikes per second during the stimulus and the number of spikes per second during baseline (Manunta and Edeline, 1999).

To assess whether norepinephrine influences auditory encoding, a pattern classifier was used to test how an individual cell's temporal patterning of response to each stimulus was distinguishable from its response to other stimuli in the presence or absence of norepinephrine. A customized MATLAB (version 8.1) script was written using the built-in function classify. Spike trains were binned in 160-2000 ms intervals, and all spikes in each bin were summed to yield a representation of the firing pattern in terms of the number of spikes/bin. We used a hold-one-out cross-validation technique to train and test the classifier. Because there were a total of 20 trials in each recording, the classifier was trained using the spiking pattern (spikes/bin) from a subset of 19 trials to classify those 19 trials into the four different stimulus categories (CON1, CON2, HET, $\mathrm{WN}$ ). The classifier then assigned the remaining spiking pattern (the test pattern) to one of the four stimulus categories, based on its similarity to the learned categories. This was repeated 20 times, such that each of the 20 recorded trials served as the test pattern on one occasion. Classification accuracy (\% correct) was calculated based on the success rate of the classifier for correctly identifying the category of the stimulus that elicited the held-out (test) spiking pattern.

For the electrophysiological recordings, the changes in different parameters across different treatments were analyzed using two-way repeated-measures (TW-RM) ANOVA, where sound stimuli and treatments were used as factors. When sphericity was violated, GreenhouseGeisser correction was used for adjustment. Post hoc comparisons were performed with nonparametric paired Wilcoxon signed-rank tests (pW-SRT).

\section{Results}

Norepinephrine enhances the auditory-evoked activity and signal-to-noise ratio for NCM auditory neurons

In vivo retrodialysis was coupled with extracellular electrophysiological recording to test whether norepinephrine $(0.1 \mathrm{mM})$ has an effect on auditory-evoked activity in the NCM (Fig. $1 A ; N=$ 17 animals). An example multiunit response from one animal is shown in Figure 1C. Upon inspection of histological sections, we noted that retrodialysis probes were positioned in the rostral auditory lobule (NCM/CMM boundary along the mesopallial lamina) in 5 experiments, whereas the remaining $(N=12)$ experiments had probes correctly placed in the caudal NCM. We therefore restricted our analyses to the experiments in which the probes were correctly positioned within caudal NCM $(N=12$ birds). Single units from the caudal NCM were sorted using principal component analysis (Fig. $1 B$ ). For $N=18$ auditoryresponsive single units (stimulus-evoked firing - spontaneous 

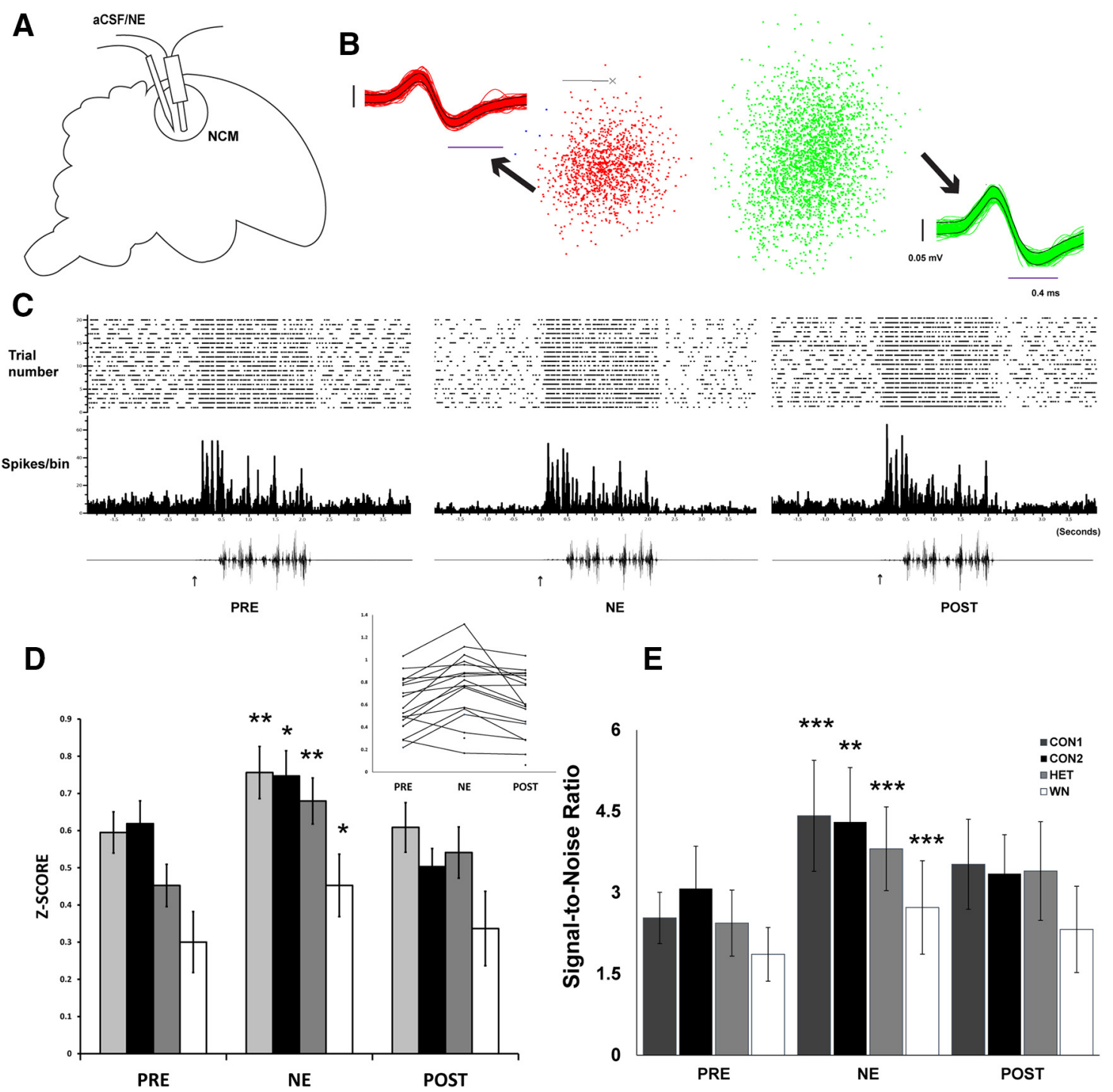

E

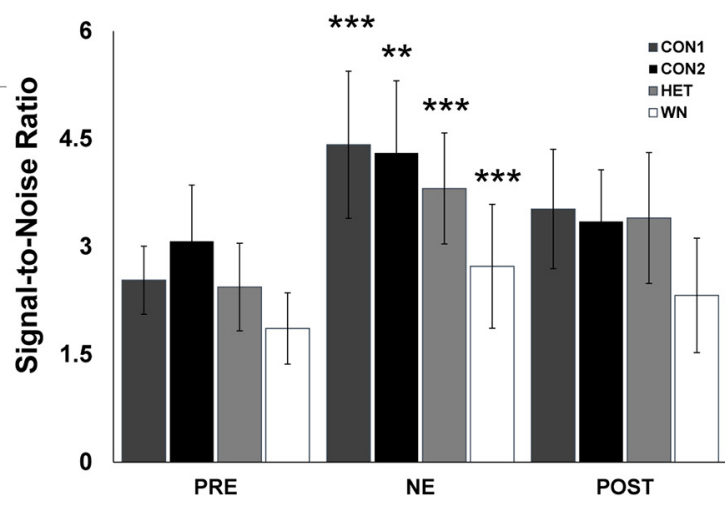

Figure 1. Norepinephrine modulates responses to auditory stimuli in caudal NCM. $A$, Experimental setup. In urethane-anesthetized animals, a microdialysis probe was inserted into the NCM. An electrode was inserted caudal to the probe. Norepinephrine dissolved in aCSF $(0.1 \mathrm{~mm})$ was administered through the probe. $\boldsymbol{B}$, A representative plot of single-unit clusters isolated using principal component analysis. Insets, 100 sequential traces overlaid from identified neurons. C, A typical multiunit response to a conspecific song (CON1) from one animal. Raster plots of spikes incorporated in z-score analysis (top) and peristimulus time histograms ( $100 \mathrm{~ms}$ bins, middle) relative to the onset to the stimulus (arrows, oscillograms at bottom). D, E, Norepinephrine enhances the auditory $Z$-score $(\boldsymbol{D})$ and signal-to-noise ratio $(\boldsymbol{E})$ similarly in NCM single units. Data are mean \pm SEM $(N=18)$. Inset, Within cell comparison of $z$-score for the CON1 stimulus. CON, Conspecific zebra finch songs; HET, heterospecific Bengalese finch song; WN, white noise ${ }^{*} p<0.05$ (vs PRE). ${ }^{* *} p<0.01$ (vs PRE). ${ }^{* * *} p<0.001$ (vs PRE).

(prestimulus) firing $>0$ ), norepinephrine significantly increased the auditory $z$-score for all stimuli (Fig. 1D; TW-RM ANOVA, main effect treatment: $F_{(2,30)}=13 p=0.00011$; main effect stimuli: $F_{(1.2,18)}=13 p=0.0013$; treatment $\times$ stimulus interaction: $F_{(6,90)}=6.8 p=0.0000054 ;$ pW-SRT: PRE vs NE, CON1, $p=$ $0.0041 ; \mathrm{CON} 2, p=0.021 ; \mathrm{HET}, p=0.0012 ; \mathrm{WN}, p=0.044)$. The $z$-score values returned back to baseline levels after washout (pW-SRT: NE vs POST, CON1, $p=0.0018$; CON2, $p=0.00048$; HET, $p=0.0090$; WN, $p=0.012$ ), indicating that the effect of norepinephrine was reversible. We also calculated the signal-tonoise ratio, which has traditionally been used to measure how sensory neurons are modulated by norepinephrine to enhance signal detection (Foote et al., 1975; Manunta and Edeline, 1997). As with $z$-scores, signal-to-noise ratios significantly increased with norepinephrine infusion for all stimuli (Fig. 1E; TW-RM ANOVA, main effect treatment, $F_{(2,34)}=19, p=0.0033$; main effect stimuli, $F_{(1.1,18)}=20 p=0.00021$; treatment $\times$ stimulus interaction, $F_{(2.0,52)}=p=0.053$; pW-SRT: PRE vs NE, CON1, $p=0.00025 ; \mathrm{CON} 2, p=0.0015 ; \mathrm{HET}, p=0.00021 ; \mathrm{WN}, p=$ 0.00058). The signal-to-noise values returned back to baseline levels after washout (pW-SRT: NE vs POST, CON1, $p=0.0069$; $\mathrm{CON} 2, p=0.00049$; HET, $p=0.036$; $\mathrm{WN}, p=0.0030$ ). As in many sensory systems, the signal-to-noise ratio was highly correlated with other measures of auditory processing. The $z$-score values and signal-to-noise ratio during the PRE period were significantly correlated (Pearson correlation, $r=0.76, p=0.00021$ ), and the response strength values (firing activity during stimulus - prestimulus firing) were also highly correlated with signalto-noise ratio $(r=0.74, p=0.00066)$.

\section{Norepinephrine suppresses spontaneous firing}

The changes in signal-to-noise ratio may be due to changes in spontaneous activity, auditory-evoked activity, or both (Foote et al., 1975; Manunta and Edeline, 1997). In the rodent auditory cortex, norepinephrine causes increases in signal-to-noise ratio in cells whose spontaneous activity is concurrently suppressed 
(Manunta and Edeline, 1997). Thus, in the NCM neurons recorded here, we tested whether the norepinephrineinduced enhancement in signal-to-noise ratio was due to a decrease in spontaneous activity (Fig. 1). In the same units isolated above $(N=18)$, we observed that norepinephrine caused a significant decrease in the number of spikes and bursts during spontaneous firing (i.e., activity before auditory stimulus presentation) while having no significant effects on auditoryevoked firing during stimuli (Fig. 2A,C; pW-SRT: PRE vs NE, number of spikes during spontaneous firing $[p=0.014]$ and during presentation of stimuli $[p=$ $1.00]$; number of bursts during spontaneous firing $[p=0.0069]$ and during presentation of stimuli $[p=0.90]$, data not illustrated). Furthermore, the variance in the number of spikes was significantly reduced for spontaneous firing, but it did not change for firing during stimuli (data not illustrated; pW-SRT: PRE vs NE, baseline, $p=0.012$; during stimuli, $p=0.43$ ). The percentages of spikes found within bursts was decreased following norepinephrine infusion for spontaneous firing but not during the presentation of stimuli (data not illustrated, pW-SRT: PRE vs NE, baseline, $p=0.0090$; during stimuli, $p=$ 0.32). In mammalian auditory cortex, norepinephrine is known to alter the firing frequency both before stimulus onset and during the stimulus, and the degree of change in spontaneous firing is related to the change in auditory-evoked firing (Foote et al., 1975; Manunta and Edeline, 1997, 1999). To determine whether this relationship holds true in avian auditory cortex, we examined correlations between auditory-evoked and spontaneous activity. During the pre-NE period, there was a significant correlation across our population of single units between the spontaneous firing rate and firing rate during stimulus presentations (data not illustrated; Pearson correlation, $r=0.79, p=$ $0.000098)$. Then, taking into account the changes during norepinephrine treatment, the change in spontaneous firing frequency upon norepinephrine retrodialysis positively correlated with the NEinduced changes in firing frequency evoked by auditory stimuli (averaged across all four auditory stimuli; Fig. 2A; Pearson correlation, $r=0.84, p=$ 0.000011 ) and the change in the number of bursts for spontaneous firing positively correlated with the change in the number of bursts for firing driven by auditory stimuli (also averaged across all four auditory stimuli; data not illus-
A

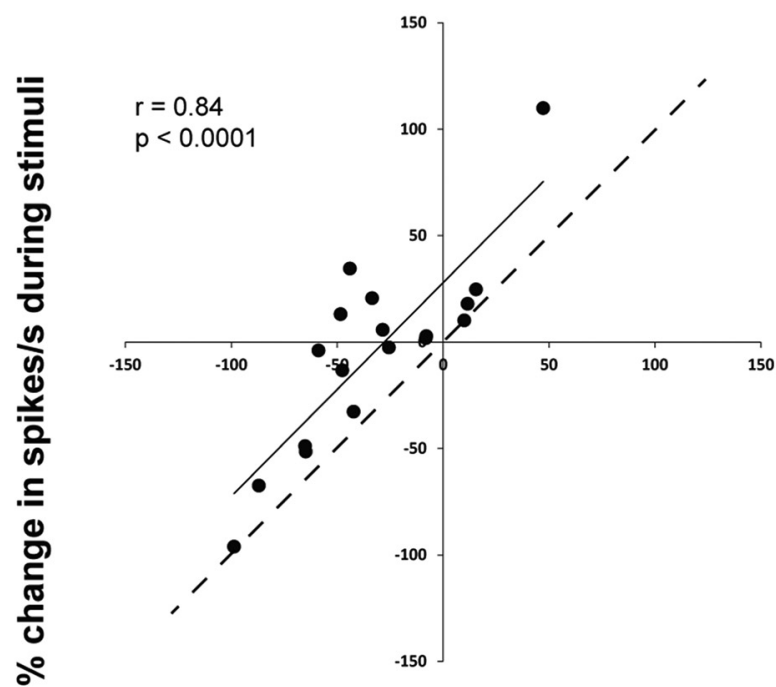

$\%$ change in spontaneous spikes/s

B

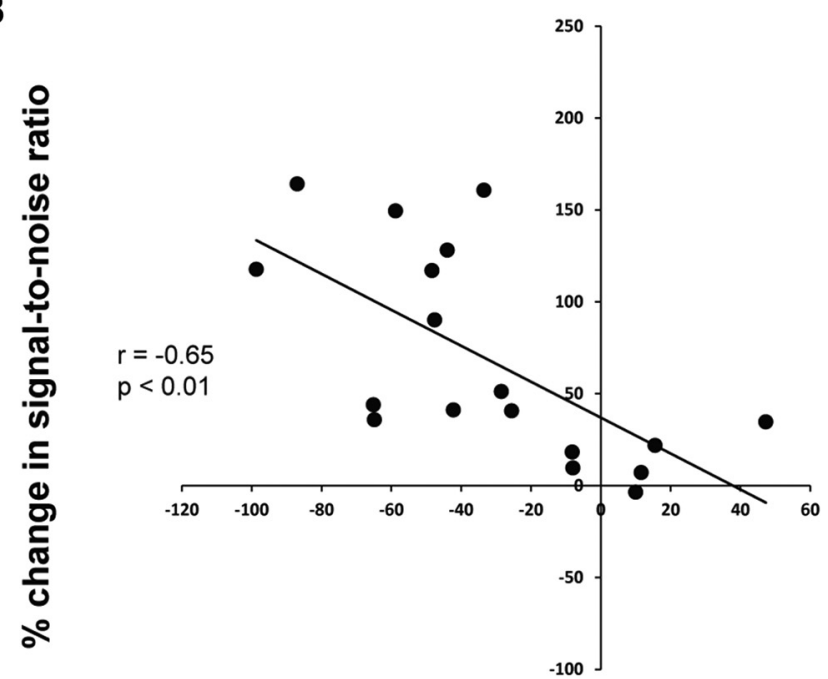

$\%$ change in spontaneous spikes/s

C
Spontaneous

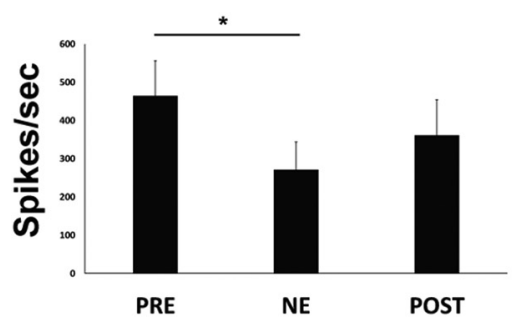

\section{During stimuli}

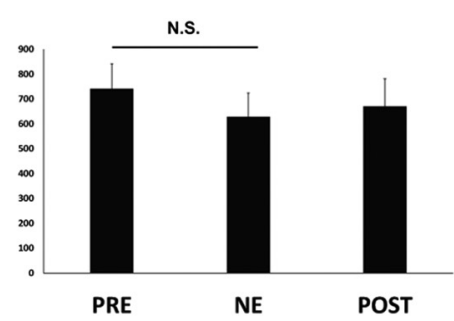

Figure 2. Norepinephrine induces changes in spontaneous activity and firing during stimuli, which result in the enhancement of the auditory signal-to-noise ratio. Spontaneous activity was measured $2 \mathrm{~s}$ before the beginning of stimuli; spiking activity during auditory stimuli was extracted for $2 \mathrm{~s}$ from the beginning of the stimuli. A significant correlation between the percentage change in the number of spontaneous spikes and the percentage change in signal-to-noise ratio for CON1 ( $\boldsymbol{A}$ ) and percentage changes in number of spikes during stimuli (averaged across all four stimuli) $(\boldsymbol{B}) . r$ and $p$ values are derived from Pearson correlations. $\boldsymbol{C}$, Norepinephrine suppresses spontaneous firing (left) but does not change the firing rate during stimuli (averaged across all stimuli, right). Dashed line indicates a unity line. Data points above this line indicate an increase in signal-to-noise ratio (mean \pm SEM). N.S., Not significant, $p>0.05 .{ }^{*} p<0.05$ (vs PRE). 
A

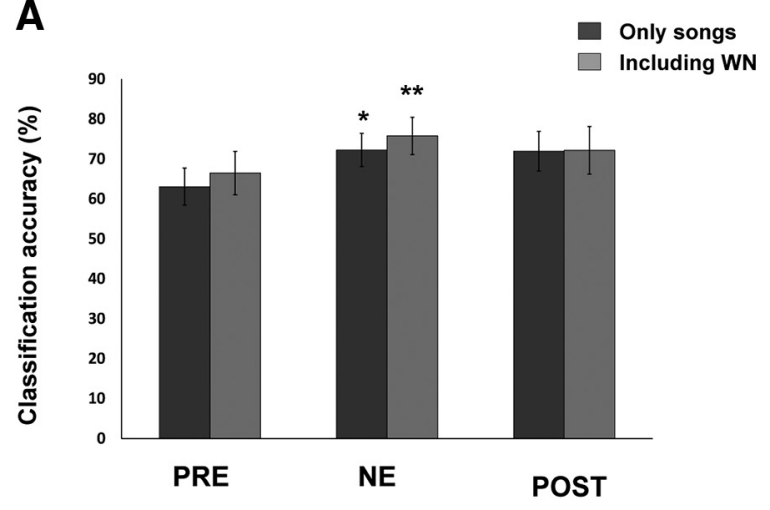

B
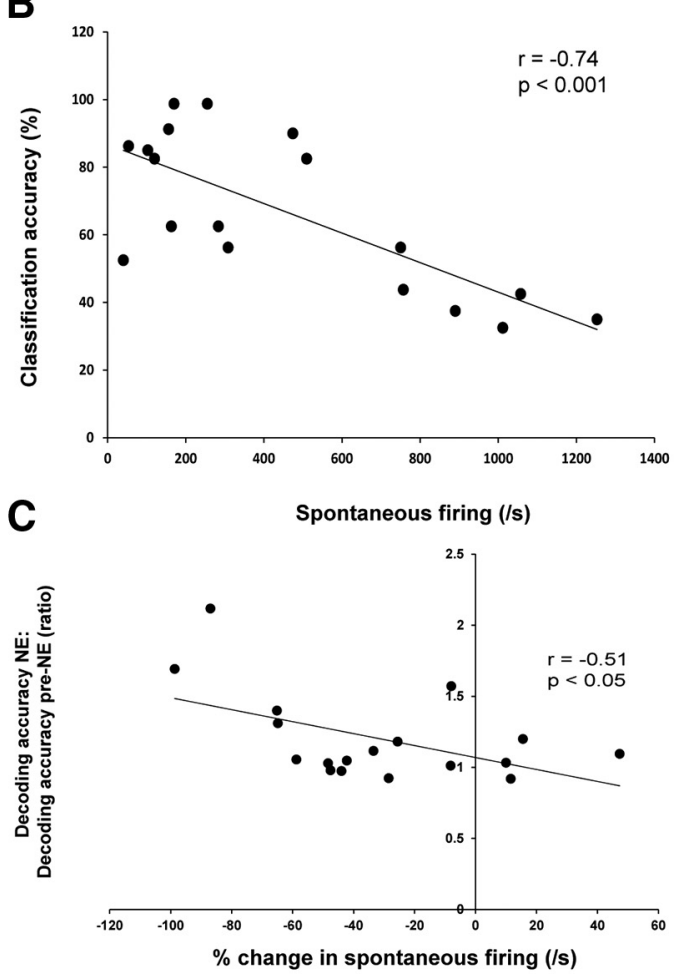

Figure 3. Norepinephrine enhances neural coding for complex vocalizations (i.e., song). $A$, Classification accuracy (mean \pm SEM) among four stimuli, including white noise (with WN, bin size 160 $\mathrm{ms}$ ) and among songs (no WN, bin size $400 \mathrm{~ms}$ ). ${ }^{*} p<0.05$ (within-group comparison vs PRE). ${ }^{* *} p<0.01$ (within-group comparison vs PRE). $\boldsymbol{B}$, A significant correlation between spontaneous firing and classification accuracy in the absence of treatment (top). $C$, A significant correlation between percentage change in spontaneous firing induced by NE and relative classification accuracy during NE infusion (bottom).

trated, Pearson correlation, $r=0.88, p=0.0000015)$. Therefore, for our population of single NCM neurons, the degree of enhancement of evoked firing enabled by norepinephrine was directly related to the degree of concurrent suppression of spontaneous firing activity.

In rodent auditory cortex, Manunta and Edeline (1999) reported that the change in spontaneous firing frequency by norepinephrine is correlated with an enhancement in signal-to-noise ratio. During the pre-NE period, there was a significant correlation between spontaneous firing and signal-to-noise ratio for songs but not for white noise (data not illustrated; Pearson correlations; CON1: $r=-0.71, p=0.0011$; CON2: $r=-0.72, p=$ 0.00076; HET: $r=-0.60, p=0.0091$; WN $r=-0.28, p=0.26)$. With norepinephrine, the change in spontaneous firing negatively correlated significantly with the change in signal-to-noise ratio to birdsongs but not white noise (Fig. $2 B$; CON1, $r=-0.65$, $p=0.0032$; CON2, $r=-0.73, p=0.00052$; HET, $r=-0.60, p=$ 0.0083 ; WN, $r=-0.36, p=0.14$; data not illustrated for CON2, HET, and WN). Together, norepinephrine in the avian auditory NCM appears to have a similar neuromodulatory function for the processing of complex sounds, as in mammalian auditory cortex for tone processing. The observations that norepinephrine enhances the signal-to-noise ratio while also decreasing spontaneous activity then raised the question whether norepinephrine effectively changes the ability of NCM neurons to encode complex auditory stimuli.

\section{Norepinephrine significantly enhances auditory coding of complex stimuli (i.e., song)}

Norepinephrine may not only enhance the detection of stimuli but also enhance the brain's ability to accurately encode complex sounds, such as song. Using the same set of recordings $(N=18$ units), a classifier was trained to discriminate the firing patterns produced in response to the four stimuli presented during the experiments (see Materials and Methods). The classification accuracy was tested with 8 different bin sizes between 160 and 2000 $\mathrm{ms}$. The data plotted in Figure $3 A$ are from the smallest bin sizes for which the classifier could be run, using data including songs and white noise (with $\mathrm{WN}$ ) and data including songs but no white noise (without WN). The classifier we used requires at least one spike in each bin for all stimuli, to be able to find a solution.

We observed that, with smaller bin sizes, it became more likely that there was at least one bin with no spikes, which sometimes made it not possible to run the classifier. In the "with WN" condition, there is one more stimulus category (i.e., the white noise category) than in the "without WN" condition. This reduces the probability that there will exist a bin with no spikes for any stimulus and therefore allows the classifier to perform at smaller bin sizes for the "with WN" condition than in the "without WN" condition. Norepinephrine significantly increased classification accuracy for all bin sizes tested (pW-SRT: PRE vs NE, $2000 \mathrm{~ms}$, $p=0.0052 ; 1000 \mathrm{~ms}, p=0.023 ; 667 \mathrm{~ms}, p=0.015 ; 500 \mathrm{~ms}, p=$ $0.0029 ; 400 \mathrm{~ms}, p=0.00071 ; 267 \mathrm{~ms}, p=0.0021 ; 200 \mathrm{~ms}, p=$ $0.0022 ; 160 \mathrm{~ms}, p=0.0074$; "with WN"; Fig. $3 A$ ). Therefore, norepinephrine appears to have an effective role in enhancing the coding accuracy of auditory stimuli in NCM neurons, across a variety of time windows.

Because there was also a significant decrease in spontaneous firing with norepinephrine (see above), we speculated that a component of spontaneous firing may be acting as background "noise" and interfering with classification accuracy. To assess whether there is a simple relationship between a neuron's spon- 
taneous firing rate and its stimulus decoding accuracy in the absence of norepinephrine, correlations between these two parameters were calculated. Within the pre-NE period, the decoding accuracy of the classifier was significantly inversely correlated with spontaneous firing across the population of NCM neurons (Fig. 3B; Pearson correlation, $r=-0.74, p=0.00043$ ). That is, the lower the spontaneous firing rate of a neuron measured before stimulus onset, the higher the decoding accuracy achieved by the classifier for the firing patterns elicited in that neuron during auditory stimulus presentation. In contrast, decoding accuracy for firing patterns elicited by auditory stimuli was not correlated with firing rate during those same stimuli (data not illustrated; Pearson correlation, $r=-0.41, p=0.090$ ). Therefore, low spontaneous firing is associated with more precise stimulus encoding by NCM neurons, which is consistent with the hypothesis that a component of spontaneous firing is likely to be contributing "noise" to the ongoing auditory encoding of NCM neurons. This interpretation is in line with the observation noted earlier that NE decreased the spontaneous firing rate, but not the firing rate during stimuli (Fig. 2C). In further agreement with this interpretation, the ratio of the decoding accuracy during NE to decoding accuracy pre-NE was significantly negatively correlated with both the percentage change in spontaneous firing (Fig. 3C; Pearson correlation, $r=-0.51, p=0.032$ ) and the percentage change in firing during stimuli (data not illustrated; Pearson correlation, $r=-0.61, p=0.0076)$. In summary, our findings suggest that norepinephrine modulates songbird auditory neurons by enhancing signal detection and decoding accuracy via reducing background noise firing.

\section{An $\alpha 2$-adrenergic receptor (AR $\alpha 2$ ) agonist mimics the effects of norepinephrine}

In rodent auditory cortex, the NE-induced decrease in spontaneous activity is similar to GABA-induced decreases in spontaneous activity (Manunta and Edeline, 1997), and NE-induced increases in inhibitory currents are mediated by an AR $\alpha 2$ mechanism (Salgado et al., 2011b). Therefore, we predicted in the NCM that activation of $\mathrm{AR} \alpha 2$ by an agonist, clonidine, would mimic the effects of norepinephrine in the NCM. The effect of clonidine was tested on a new set of birds ( $N=6$ animals, $N=13$ units) with stereotaxic coordinates directed at the caudal NCM. We used two different concentrations $(0.5$ and $5 \mathrm{~mm})$ derived from dosedependent effects of clonidine reported in other regions in the zebra finch brain (Cardin and Schmidt, 2004). Like norepinephrine, clonidine significantly enhanced NCM signal-to-noise ratio (Fig. 4A, top; pW-SRT: PRE vs HIGH, CON1, $p=0.011$; CON2, $p=0.0016$; HET, $p=0.0051 ; \mathrm{WN}, p=0.030)$, decreased the number of spikes during auditory presentations (Fig. $4 A$, middle; pW-SRT: PRE vs HIGH, CON1, $p=0.017$; CON2, $p=0.030$; HET, $p=0.021$; WN, $p=0.069$ ), and decreased spontaneous spiking (Fig. $4 A$, bottom; pW-SRT: PRE vs HIGH, $p=0.011$ ). This effect was dose-dependent, as the low dose of clonidine had mixed effects (Fig. 4A; pW-SRT, PRE vs LOW, signal-to-noise ratio: $\mathrm{CON} 1, p=0.44 ; \mathrm{CON} 2, p=0.0041$; $\mathrm{HET}, p=0.042 ; \mathrm{WN}$, $p=0.36$; spikes during stimuli: $\mathrm{CON} 1, p=0.37$; $\mathrm{CON} 2, p=0.83$; HET, $p=0.49$; WN, $p=0.24$; spontaneous firing: $p=0.14$ ). Moreover, like norepinephrine, the clonidine-induced change in spontaneous firing was correlated with the clonidine-induced change in firing during stimuli (Fig. $4 C$; Pearson correlations, all stimuli combined, LOW, $r=0.90, p=0.000022$, data not illustrated; HIGH, $r=0.93, p=0.0000030$ ), and the clonidineinduced change in spontaneous firing was correlated with the clonidine-induced change in signal-to-noise ratio (Fig. 4D; Pear- son correlations, all stimuli combined, LOW, $r=-0.77, p=$ 0.0019 , data not illustrated; HIGH, $r=-0.57, p=0.038)$. We also tested the effect of cirazoline, which is a AR $\alpha 1$ agonist and AR $\alpha 2$ antagonist (a new set of $N=2$ birds, $N=4$ units) (Ruffolo and Waddell, 1982). In all cells tested, cirazoline caused a mean increase in spontaneous activity and the firing during auditory stimuli, while having no discernible influence on the signal-tonoise ratio (Fig. $4 B$ ), although these changes did not reach statistical significance ( $\mathrm{pW}$-SRT, PRE vs LOW, signal-to-noise ratio: CON1, $p=0.58$; CON2, $p=1.0$; HET, $p=0.58$; WN, $p=1.0$; spikes during stimuli: CON1, $p=0.10$; CON2, $p=0.10$; HET, $p=0.10 ; \mathrm{WN}, p=0.10$; spontaneous firing: $p=0.10$; PRE vs $\mathrm{HIGH}$, signal-to-noise ratio: $\mathrm{CON} 1, p=0.20$; $\mathrm{CON} 2, p=0.36$; HET, $p=0.10$; $\mathrm{WN}, p=0.58$; spikes during stimuli: $\mathrm{CON} 1, p=$ 0.10 ; CON2, $p=0.10$; HET, $p=0.10$; $\mathrm{WN}, p=0.10$; spontaneous firing: $p=0.10$ ). It is important to note that some of the effects of cirazoline could be due to an $\alpha 2$ antagonism, although a separate $\alpha 2$ antagonist we tested, idazoxan, did not influence any of the tested measures ( $N=2$ units, data not illustrated). In summary, the major actions of norepinephrine on NCM auditory signal detection were mimicked by the AR $\alpha 2$ agonist, clonidine.

\section{Norepinephrine does not affect estradiol levels in the NCM}

The NCM region of the songbird is enriched with aromatase (Saldanha et al., 2000; Peterson et al., 2005); therefore, estradiol may act as an intermediary mechanism for the actions of norepinephrine described above. Estradiol was shown in single NCM units to increase the $z$-score values to multiple stimuli (RemageHealey and Joshi, 2012) in a similar fashion as described here for norepinephrine. Therefore, we tested the hypothesis that norepinephrine regulates auditory processing via the regulation of local estradiol levels.

To test the direct effect of norepinephrine on estradiol levels, in vivo retrodialysis was used in a new set of awake behaving animals $(N=18)$ to measure the changes in local estradiol levels in NCM in response to norepinephrine infusions $(0$, 0.01 , and $0.1 \mathrm{~mm}$; Fig. $5 A$ ). There were no significant changes in NCM estradiol levels in response to norepinephrine infusions (Fig. $5 B, C$; Friedman ANOVA: $0 \mathrm{~mm}, \chi^{2}=2.7, N=17$, $\mathrm{df}=3, p=0.44 ; 0.01 \mathrm{~mm} \mathrm{NE}, \chi^{2}=4.2, N=14, \mathrm{df}=3, p=$ 0.24; $0.1 \mathrm{~mm} \mathrm{NE}, \chi^{2}=3.4, N=15$, $\left.\mathrm{df}=3, p=0.33\right)$. The result was also not dependent on the time of the experiment (Fig. $5 C$ ): all $p>0.05$ for morning ( $N=13$ experiments), afternoon ( $N=15$ experiments), and night ( $N=8$ experiments). We also scored the birds' activity levels during the norepinephrine infusions in the daytime. There was no effect of norepinephrine retrodialysis into NCM on locomotor activity (number of hops/min: control: $2.1 \pm 0.67, N=9 ; 0.01$ mM NE: $7.21 \pm 3.6, N=11 ; 0.1 \mathrm{~mm} \mathrm{NE:} 5.5 \pm 2.2, N=10$ experiments), indicating that birds were equivalently behaviorally responsive during the retrodialysis treatments.

To further evaluate this hypothesis, in a new set of animals, we tested the effects of adrenergic antagonists on estradiol levels to determine whether blockade of endogenous norepinephrine signaling would influence local NCM estradiol levels $(N=20)$. Because all AR subtypes are expressed in the NCM (Velho et al., 2012), prazosin, RX821001, or propanolol was infused to block $\alpha 1, \alpha 2$, and $\beta$ receptors, respectively (all doses $=0.1 \mathrm{~mm}$ ). None of the adrenergic antagonists had detectable effects on local estradiol levels within NCM (mean estradiol levels relative to baseline during antagonist infusions, vehicle: $1.1 \pm 0.15, N=18$ experiments; prazosin: $1.2 \pm 0.10, N=16$ experiments; propanolol: 
A
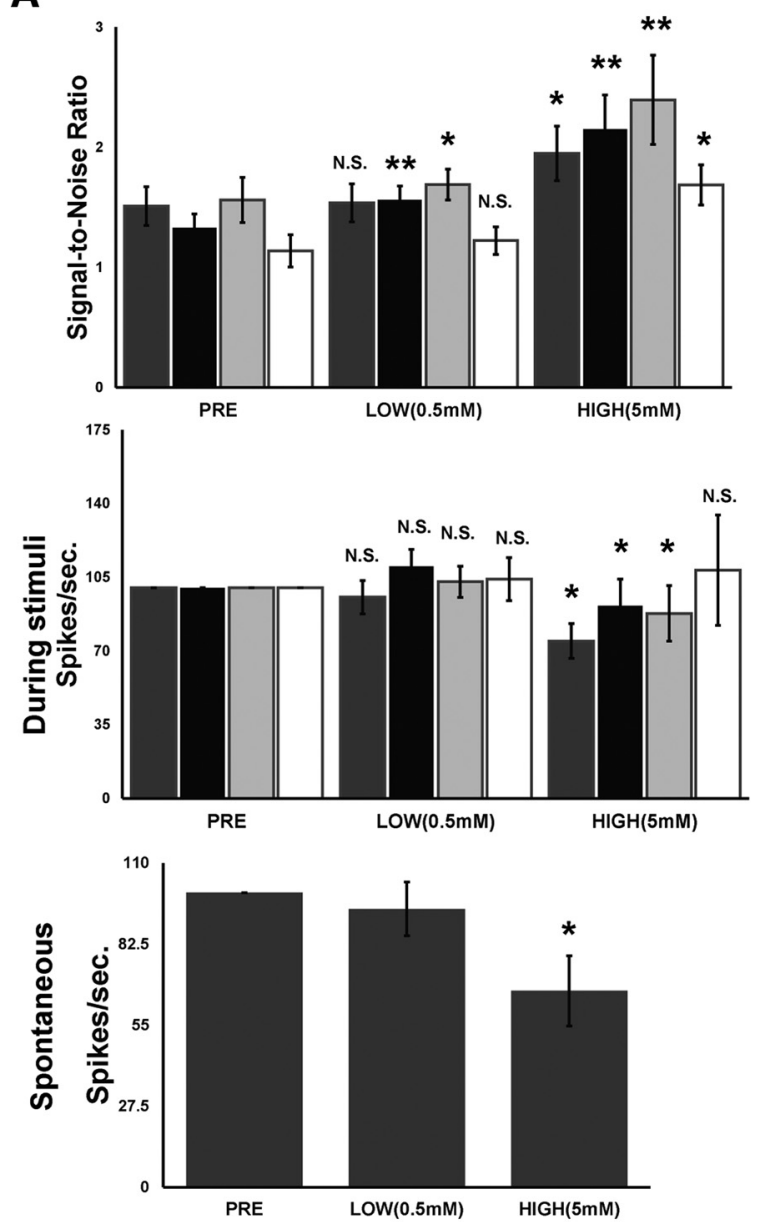

Clonidine

C

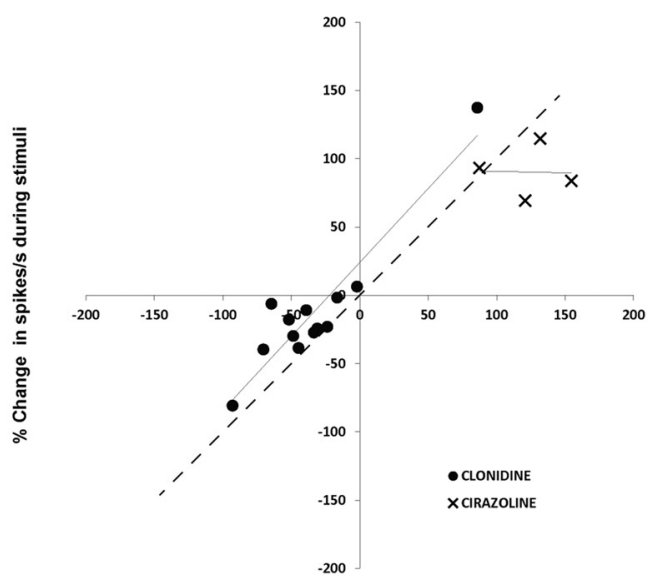

$\%$ Change in spontaneous spikes/s
B
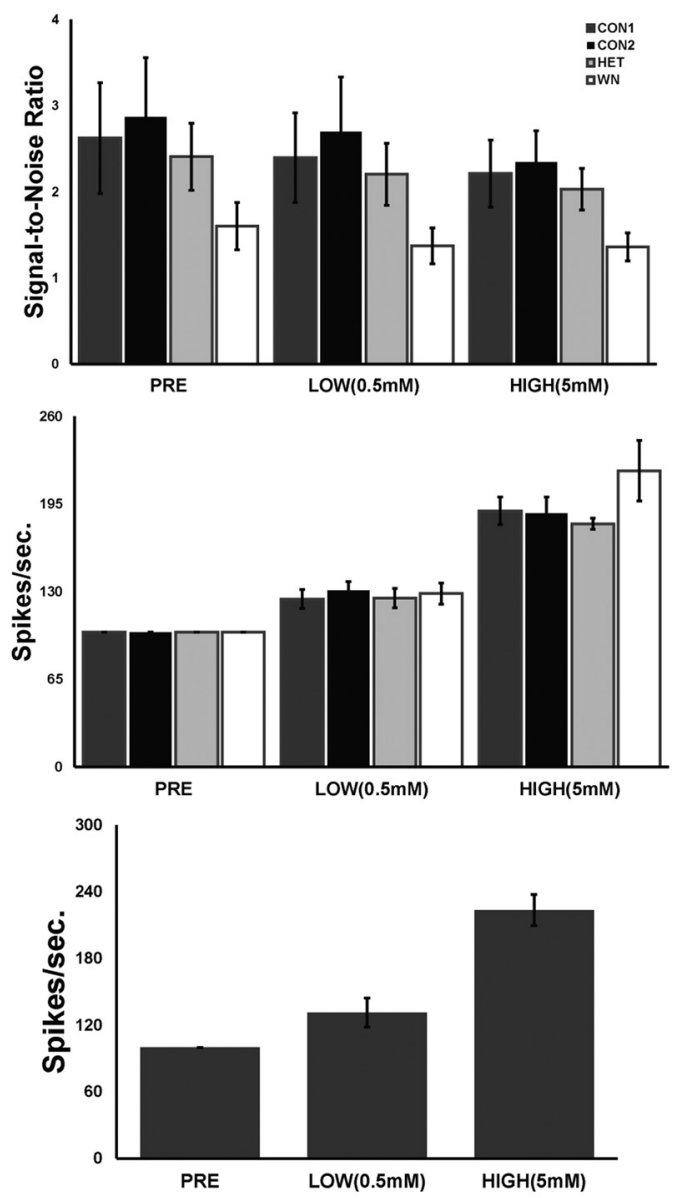

Cirazoline

D

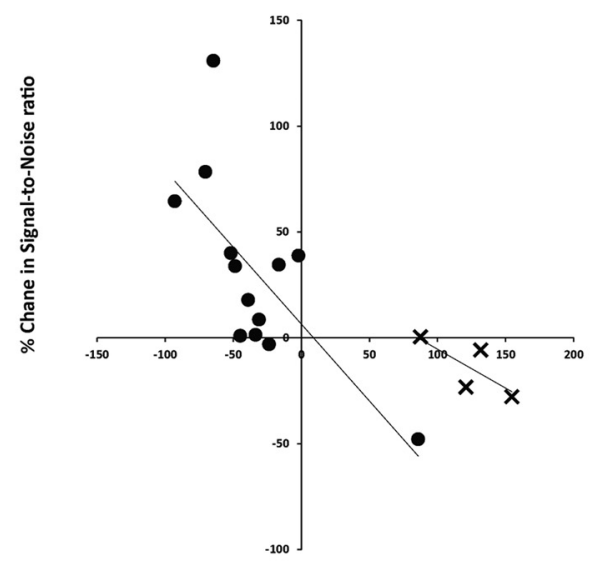

\% Change in spontaneous spikes/s

Figure 4. The AR $\alpha 2$ agonist clonidine mimics the effects of norepinephrine in the NCM. $A, B$, Signal-to-noise ratio is enhanced by clonidine at both low and high dose (mean \pm SEM, top). Both spiking activity during stimuli (middle) and spontaneous spikes (bottom) were suppressed by clonidine. There was a mean increase for cirazoline but was not statistically significant (spikes during stimuli normalized to "PRE" values; mean \pm SEM). The number of spontaneous spikes; data are mean \pm SEM. N.S., Not significant, $p>0.05 .{ }^{*} p<0.05$ (vs PRE). ${ }^{* *} p<0.01$ (vs PRE). C, A significant correlation between percentage changes in spontaneous spikes and the percentage changes in the number of spikes during stimuli for clonidine $(r=0.93, p=0.0000030$; for similar findings with norepinephrine, compare with Fig. 2A). There was no relationship for cirazoline $(r=-0.031, p=0.96)$. $\boldsymbol{D}$, A significant correlation between percentage changes in number of spontaneous spikes and percentage changes signal-to-noise ratio to CON1 for clonidine $(r=-0.70, p=0.0067)$ but not for cirazoline $(r=-0.75, p=0.24)$. 
A
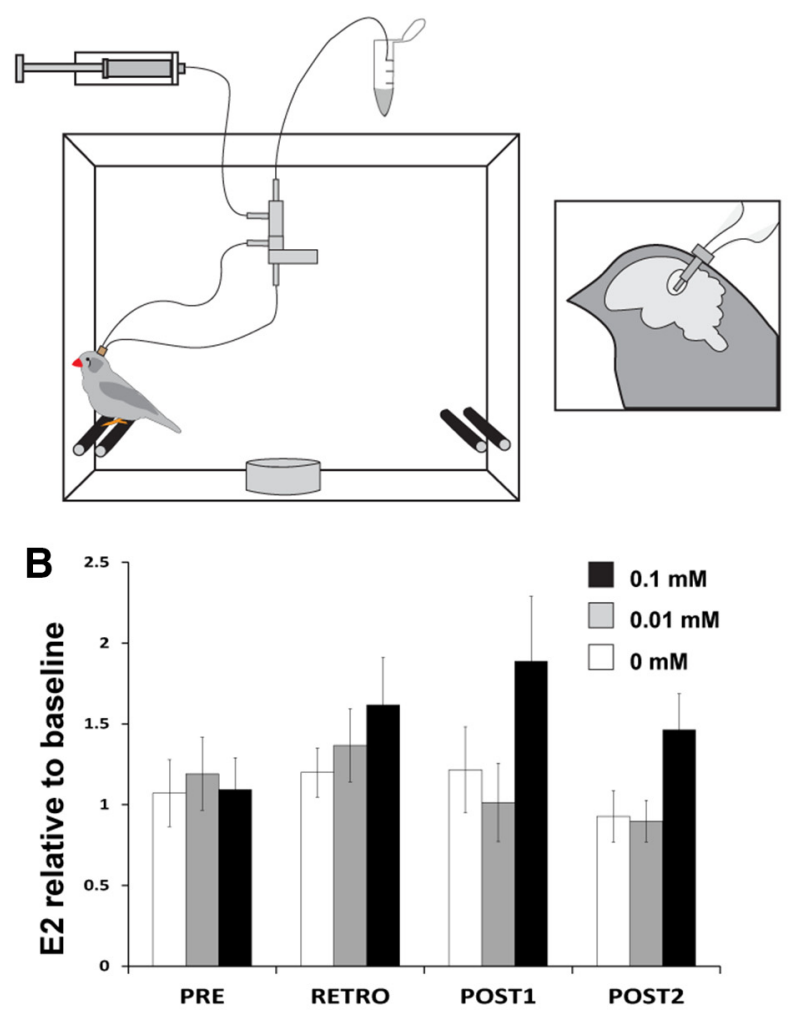

C
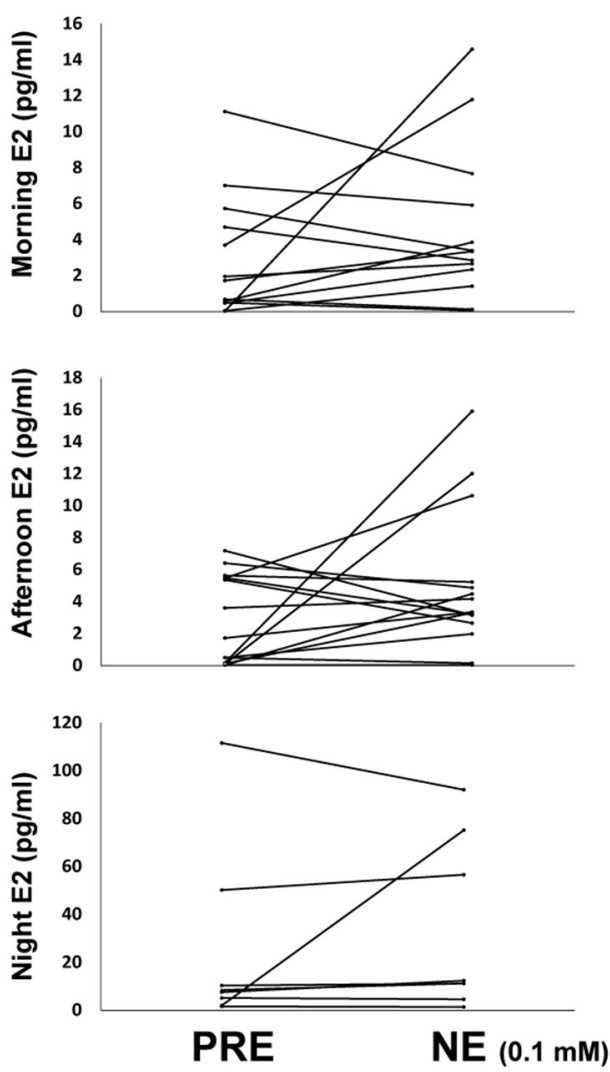

Figure 5. Norepinephrine has no effect on local estradiol levels in NCM. $\boldsymbol{A}$, Experimental setup for in vivo reverse microdialysis. A microdialysis probe was inserted into the caudal NCM through a guide cannula. The solutions were delivered through tubing and a microdialysis swivel, and all manipulations were external to a sound isolation chamber to minimize disturbance. $\boldsymbol{B}$, Estradiol (E2) levels relative to baseline (mean \pm SEM) before (PRE), during (RETRO), and after (POST1 and POST2) norepinephrine infusions. Dialysates were collected every $30 \mathrm{~min}$. $0 \mathrm{~mm}$ NE, $N=17 ; 0.01 \mathrm{~mm}$ $\mathrm{NE}, N=14 ; 0.1 \mathrm{~mm} \mathrm{NE}, N=15$. C, Estradiol levels in individual birds before (PRE) and during ( $0.1 \mathrm{~mm} \mathrm{NE})$ norepinephrine infusions during experiments conducted in the morning (9:30 A.M., $N=$ 13 , top), afternoon (2 P.M., $N=15$, middle), and night (9:30 P.M., $N=8$, bottom).

$1.7 \pm 0.61, N=11$ experiments; RX821001: $2.0 \pm 0.55, N=14$ experiments) (pW-SRT: Pre vs during antagonist, vehicle, $p=$ 0.28 ; prazosin, $p=0.62$; propanolol, $p=1.0$; $\mathrm{RX} 821001, p=$ $0.19)$. Together, these results indicate that norepinephrine signaling does not directly impact local forebrain estradiol levels, and raises the possibility that the effects of norepinephrine on the electrophysiology of NCM neurons are independent of local estradiol synthesis.

The effects of norepinephrine on NCM neuronal activity are not dependent on local estradiol synthesis

To directly test whether or not the effects of norepinephrine on auditory-evoked responses are dependent on local estrogen synthesis within NCM, estradiol production was blocked using retrodialysis of the specific aromatase inhibitor, fadrozole $(100-500 \mu \mathrm{M})$ (Wade et al., 1994) during norepinephrine retrodialysis. In a separate set of animals $(N=10)$, for $N=20$ single units in NCM, the $z$-score response to auditory stimuli was recorded before and during fadrozole infusion and then during norepinephrine and fadrozole coinfusion. Norepinephrine $(0.1 \mathrm{~mm})$ significantly enhanced auditory-evoked responses even in the presence of fadrozole (Fig. 6A; TW-RM ANOVA: main effect stimuli: $F_{(1.3,25)}=6.8, p=0.0096$; main effect treatment: $F_{(2.2,42)}=4.0, p=0.022$; treatment $\times$ stimulus interaction: $F_{(4.7,88)}=2.7, p=0.027$; pW-SRT: PREFAD vs $\mathrm{FAD}+\mathrm{NE}, \mathrm{CON} 1, p=0.00032$; CON2, $p=0.0014$; HET, $p=0.00032 ; \mathrm{WN}, p=0.046)$. Moreover, the degree of change in $z$-score values with $\mathrm{NE}$ infusion were not significantly dif- ferent from the same measure collected in the first experiment we conducted with norepinephrine in the absence of fadrozole treatment (Student's $t$ test: percentage change from PRE to NE from first experiment, $N=18$; vs percentage change from PREFAD vs FAD + NE, $N=20 ; p=0.56$, data not illustrated). Importantly, the changes in auditory-evoked responses during norepinephrine retrodialysis were not accompanied by changes in local estradiol levels in NCM (Fig. 4B; Pearson correlation: $r=0.022, p=0.95$ ), further indicating that norepinephrine alters NCM neuronal response properties but does not drive elevations in local estradiol concentrations. Together, these results indicate that the actions of norepinephrine on NCM neurons are not dependent on local estradiol synthesis in NCM.

\section{Norepinephrine synthesizing fibers are largely dissociated from estradiol synthesizing neurons}

The microdialysis and electrophysiology results above together indicate that norepinephrine enhances auditory processing and auditory coding using mechanisms that are not dependent on local estradiol synthesis in NCM. To examine the anatomical relationship between norepinephrine- and estradiol-producing neurons in NCM, DBH and aromatase enzymes were stained with double-label immunocytochemistry. In addition to a lack of double-labeled processes, we observed markedly few occurrences of direct physical interactions between aromatase-ir neurons and $\mathrm{DBH}$-ir fibers in the NCM (Fig. 6C). This anatomical dissociation within the NCM is inconsistent with a principal role of nor- 


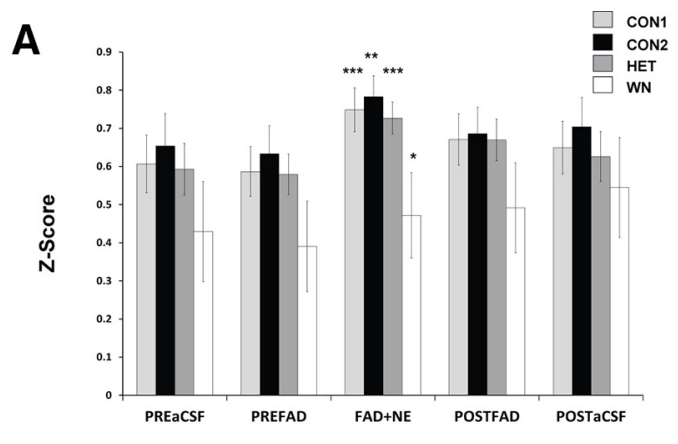

B

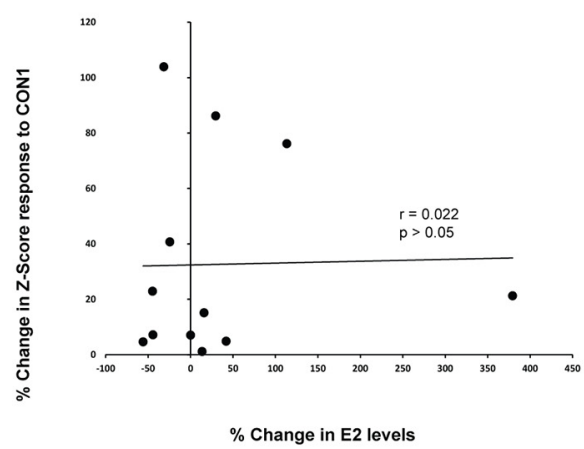

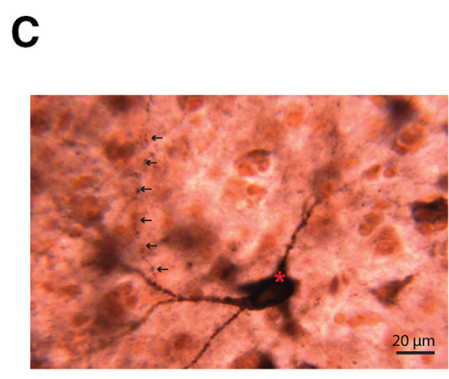

D
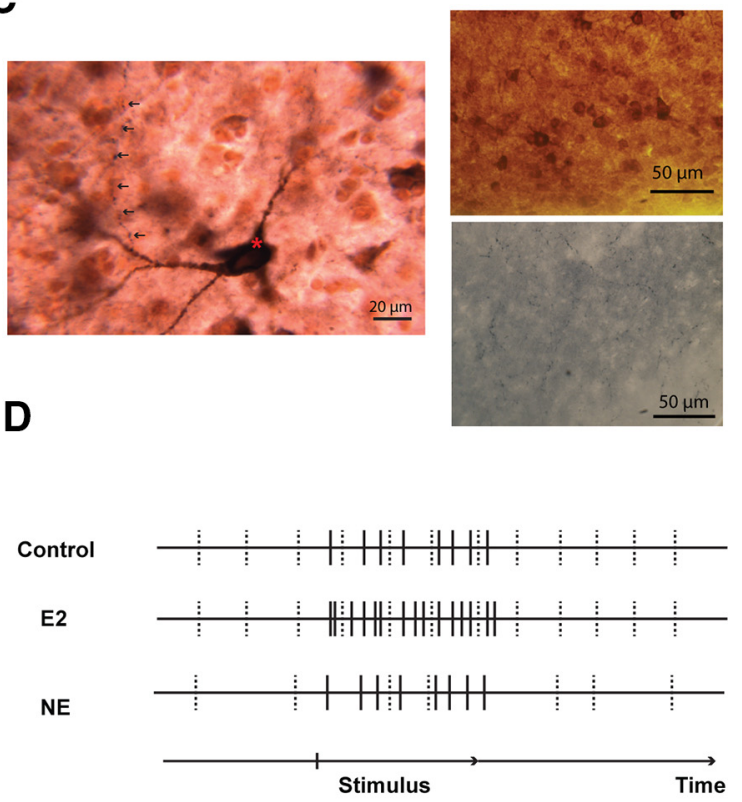

E

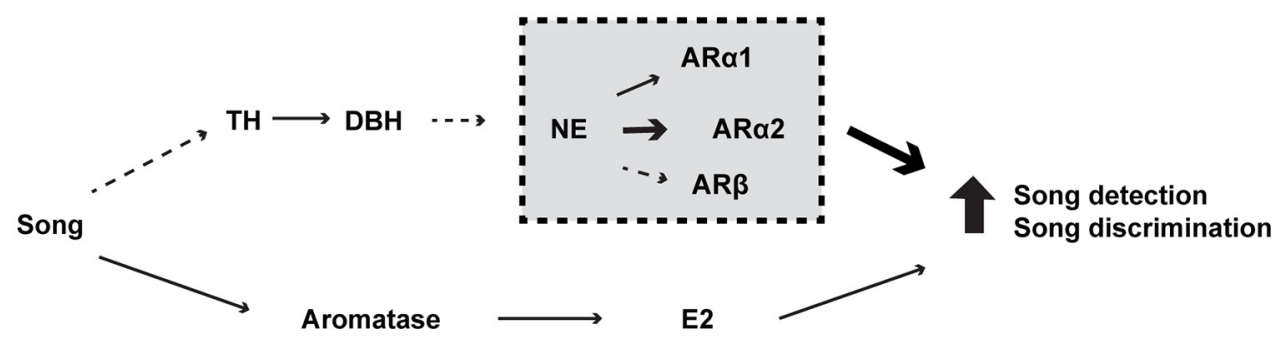

Figure 6. Norepinephrine enhances auditory-evoked responses independent of aromatase activity. $A, Z$-score (mean \pm SEM). PREaCSF, Before drug treatment; PREFAD, fadrozole pretreatment; FAD $+N E$, fadrozole and norepinephrine; POSTFAD, washout with fadrozole solution; POSTaCSF, washout with aCSF. ${ }^{*} p<0.05$, versus PREFAD. ${ }^{* *} p<0.01$, versus PREFAD. ${ }^{* * *} p<0.001$, versus PREFAD. $\boldsymbol{B}$, There was no significant correlation between percentage change in estradiol (E2) levels and percentage change in $z$-score values in response to CON1. C, Double immunostaning of DBH fibers (arrows) and aromatase neurons (red asterisk). Photomicrograph is representative of the occurrences in which DBH-ir fibers and aromatase-ir cell bodies and processes exhibited limited direct physical interactions in NCM (left). Single-label aromatase (top) and DBH (bottom) immunoreactive staining in NCM (right). D, Schematic illustration of the effects of norepinephrine and estradiol. Estradiol enhances auditory-evoked firing while norepinephrine decreases background noise, resulting in less spontaneous firing (dashed lines). E, Summary of what is known from previous findings (thin arrows) and the current study (thick arrows) in NCM. Solid arrows, tested in zebra finch; dashed arrows, demonstrated in non-zebra finch songbirds.

epinephrine to regulate aromatase-expressing neurons in the NCM.

\section{Discussion}

This study demonstrates the following: (1) norepinephrine enhances auditory detection in the songbird auditory cortex; (2) norepinephrine also enhances the coding accuracy of individual neurons for complex sounds, via a reduction in concurrent spontaneous firing; (3) norepinephrine's effects are mimicked by an $\alpha 2$ agonist; and (4) norepinephrine achieves similar effects as estradiol in modulating forebrain auditory processing in the songbird, but these effects are not directly dependent on neuroestrogen synthesis.

We show that norepinephrine similarly enhances auditoryevoked responses, signal-to-noise ratios, and auditory encoding, and does so by decreasing spontaneous activity. The amount of spontaneous firing positively correlates with firing rates during stimuli presentation, and norepinephrine decreases the degree of noise in the spontaneous activity. Furthermore, spontaneous firing rate inversely correlated with classification accuracy and signal-to-noise ratio for songs, the NE-induced change in spontaneous activity was correlated with the change in firing during stimuli, and the NE-induced change in both the spontaneous firing and firing during stimuli inversely correlated with the change in classification accuracy and signal-to-noise ratio. Thus, we propose that spontaneous activity irrelevant to auditory stimuli ("noise") is maintained throughout the stimulus-evoked response in the songbird auditory cortex and that norepinephrine increases neuronal signal detection and coding accuracy by suppressing this constitutive noise (Fig. 6D).

Our findings with zebra finch NCM build upon findings in primate and rodent auditory cortex, in which norepinephrine decreases spontaneous firing frequency and enhances the signalto-noise ratio for tones and calls (Foote et al., 1975; Manunta and Edeline, 1997, 1999), and the change in signal-to-noise ratio correlates with the change in baseline firing activity (Manunta and Edeline, 1997, 1999). To our knowledge, in the songbird auditory system, the direct effects of norepinephrine on neuronal firing frequency have been examined in only one other study (Cardin and Schmidt, 2004). Similar to our findings here for NCM, the administration of norepinephrine to nucleus interface, a premotor region essential song production, enhances stimulus selectivity in HVC, a sensorimotor region. Our results now indicate that 
norepinephrine enhances the signal-to-noise ratio and auditory coding in the songbird auditory forebrain, which likely enhances the neural discrimination of sounds that must be extracted as signals from noisy environments (Schneider and Woolley, 2013). We find it particularly interesting that norepinephrine induces a change in sensory coding accuracy via a concurrent suppression of spontaneous activity in the songbird because it provides a testable prediction for a similar mechanism for sensory coding in mammalian auditory cortex.

We report that the AR $\alpha 2$ agonist, clonidine, mimics the effects of norepinephrine on electrophysiological auditory responses, whereas the AR $\alpha 1$ agonist, cirazoline, does not. This is consistent with findings in mammalian sensory cortex, in which AR $\alpha 2$ and $\alpha 1$ agonists typically have differential effects on sensory processing (Sato et al., 1989; Nai et al., 2009; Salgado et al., $2011 b)$. Our findings identifying the AR $\alpha 2$ mechanism are particularly interesting because $\alpha 2$-mediated noradrenergic actions are key for associative plasticity in vitro in mammalian cerebellum (Carey and Regehr, 2009) and involve the suppression of the rhythmic-generating $\mathrm{I}_{\mathrm{h}}$ current (Robbins and Arnsten, 2009). Therefore, the suppression of concurrent spontaneous firing via an $\operatorname{AR} \alpha 2$ mechanism identified here may be important for associative plasticity and memory functions in the songbird NCM for complex song, during both juvenile and adult periods of song learning.

In rodent auditory cortex, norepinephrine's actions involve modulation of inhibitory neurotransmission to achieve an enhancement of signal-to-noise ratio (Foote et al., 1975; Manunta and Edeline, 1997; Salgado et al., 2011a). Differential effects of norepinephrine on spontaneous versus evoked activity in auditory cortex are thought to be achieved via differential, layerspecific actions on inhibitory interneurons (Hasselmo et al., 1997; Salgado et al., 2011b). Similarly, auditory processing and encoding depend on inhibitory neurotransmission in the songbird NCM (Pinaud and Mello, 2007; Pinaud et al., 2008; Tremere et al., 2009; Jeong et al., 2011; Tremere and Pinaud, 2011), although the layered cortical organization typical of mammals is not as evident in songbirds (Wang et al., 2010). Therefore, despite the apparently divergent neuronal architecture in the songbird auditory cortex, there appears to be a striking conservation of modulatory mechanism by norepinephrine shared between birds and mammals. Identifying specific cell types and receptor types, along with computational modeling, will further dissect how complex vocalizations are processed and modulated in higherorder circuits by norepinephrine.

Although our study confirms that neurons in NCM respond significantly to AR $\alpha 2$ agonists, it does not provide concrete evidence for the role of endogenous norepinephrine in behaving animals. Our electrophysiology experiments were conducted on urethane-anesthetized birds, which may have precluded our ability to detect endogenous actions of norepinephrine, which are highly sensitive to anesthetic state (Vazey and Aston-Jones, 2014). In this and other songbird species, however, blocking endogenous norepinephrine actions with specific receptor antagonists in awake subjects can affect auditory-dependent behavioral and immediate-early gene responses (Pawlisch et al., 2011; Velho et al., 2012). In other sensory systems, norepinephrine exerts powerful effects on behavioral discrimination of stimuli (e.g., Escanilla et al., 2010). Future experiments on songbird audition can be conducted in this species with awake recordings or in combination with locus ceruleus stimulation.

The current study provides several lines of evidence that norepinephrine does not act via changing aromatase activity in fe- male zebra finch NCM. Norepinephrine did not affect estradiol levels in NCM, and its actions on the firing properties of NCM neurons were not dependent on aromatase activity. In addition, aromatase-positive NCM neurons were largely dissociated from DBH-expressing fibers. It remains to be determined whether this pattern of modulation is similar in males because the distribution of aromatase-positive cells and fibers is reported to be sexually dimorphic in the NCM (Saldanha et al., 2000; Peterson et al., 2005). In previous studies, estradiol enhanced baselinenormalized auditory evoked responses in the NCM of both sexes (Tremere et al., 2009; Remage-Healey et al., 2010, 2012; RemageHealey and Joshi, 2012) and estradiol enhanced auditory encoding of NCM neurons (Tremere and Pinaud, 2011). We show that norepinephrine similarly enhances auditory-evoked responses and enhances auditory encoding in a similar timescale as estradiol. Importantly, estradiol enhanced spiking activity during auditory stimuli, but it had no effect on spontaneous spiking activity (Remage-Healey et al., 2010), whereas here norepinephrine decreases spontaneous activity (Fig. 6D).

The work presented here raises the possibility that norepinephrine and estradiol signaling independently regulate sensory-dependent behaviors. In songbirds, estradiol and catecholamine levels are elevated in response to song presentation in a similar timescale (Remage-Healey et al., 2008, 2012; Matragrano et al., 2012). Among vertebrates, norepinephrine release in the cortex is generally associated with arousal and attention (Aston-Jones and Bloom, 1981a, b; Aston-Jones et al., 1999). By contrast, the changes in NCM estradiol levels seem to be specific to social interactions and auditory playbacks (Remage-Healey et al., 2008, 2012). As these studies suggest, depending on the environmental context, both norepinephrine and estradiol may be released concurrently to modulate NCM sensory processing.

Norepinephrine and estradiol signaling are both required for song-induced immediate early gene ZENK (egr-1) induction in the NCM, and song discrimination and preferences (Lynch and Ball, 2008; Remage-Healey et al., 2008; Pawlisch et al., 2011; Tremere and Pinaud, 2011; Velho et al., 2012; Vahaba et al., 2013). Both aromatase and AR $\alpha 1$ mRNA are found in neurons that express inducible zenk mRNA in response to auditory stimuli in the NCM (Jeong et al., 2011; Velho et al., 2012). As shown here with norepinephrine, the change in firing rate during song stimuli with estradiol was shown to enhance the ability of NCM neurons to encode songs (Tremere and Pinaud, 2011). Together, these studies suggest that, although the upstream mechanisms appear to be different, they may activate common downstream intracellular pathways that are not currently well understood. Norepinephrine and estradiol may have differential roles in different parts of the NCM or in different cell types, and future experiments should elucidate their divergent mechanisms of action.

As in songbirds, human language processing is likely to be dependent on both neuroestrogen and catecholamine signaling. Polymorphisms in the brain-specific promoter for the aromatase gene in humans have been associated with specific language impairments (Anthoni et al., 2012), and auditory processing can vary with fluctuating estrogen levels in women (Tillman, 2010). Similarly, many mental disorders, such as schizophrenia, posttraumatic stress disorder, attention deficit hyperactivity disorder, and autism, are associated with adrenergic dysfunction as well as impairment in speech processing and dysregulation of the auditory cortex (Corbett and Stanczak, 1999; Newport and Nemeroff, 2000; Rapin and Dunn, 2003; Calhoun et al., 2004; Sweet et al., 2009). Studying the role of neuromodulators and their interac- 
tions in cortical circuits that encode and decode complex sounds may provide insight into treatments of neurological and sensoryprocessing disorders.

\section{References}

Anthoni H, Sucheston LE, Lewis BA, Tapia-Páez I, Fan X, Zucchelli M, Taipale M, Stein CM, Hokkanen ME, Castrén E, Pennington BF, Smith SD, Olson RK, Tomblin JB, Schulte-Körne G, Nöthen M, Schumacher J, Müller-Myhsok B, Hoffmann P, Gilger JW, et al. (2012) The aromatase gene CYP19A1: several genetic and functional lines of evidence supporting a role in reading, speech and language. Behav Genet 42:509-527. CrossRef Medline

Appeltants D, Ball GF, Balthazart J (2004) Catecholaminergic inputs to aromatase cells in the canary auditory forebrain. Neuroreport 15:1727-1730. CrossRef Medline

Aston-Jones G, Bloom FE (1981a) Activity of norepinephrine-containing locus coeruleus neurons in behaving rats anticipates fluctuations in the sleep-waking cycle. J Neurosci 1:876-886. Medline

Aston-Jones G, Bloom FE (1981b) Norepinephrine-containing locus coeruleus neurons in behaving rats exhibit pronounced responses to nonnoxious environmental stimuli. J Neurosci 1:887-900. Medline

Aston-Jones G, Rajkowski J, Cohen J (1999) Role of locus coeruleus in attention and behavioral flexibility. Biol Psychiatry 46:1309-1320. CrossRef Medline

Bouret S, Sara SJ (2005) Network reset: a simplified overarching theory of locus coeruleus noradrenaline function. Trends Neurosci 28:574-582. CrossRef Medline

Calhoun VD, Kiehl KA, Liddle PF, Pearlson GD (2004) Aberrant localization of synchronous hemodynamic activity in auditory cortex reliably characterizes schizophrenia. Biol Psychiatry 55:842-849. CrossRef Medline

Cardin JA, Schmidt MF (2004) Noradrenergic inputs mediate state dependence of auditory responses in the avian song system. J Neurosci 24:77457753. CrossRef Medline

Carey MR, Regehr WG (2009) Noradrenergic control of associative synaptic plasticity by selective modulation of instructive signals. Neuron 62: 112-122. CrossRef Medline

Castelino CB, Schmidt MF (2010) What birdsong can teach us about the central noradrenergic system. J Chem Neuroanat 39:96-111. CrossRef Medline

Corbett B, Stanczak DE (1999) Neuropsychological performance of adults evidencing Attention-Deficit Hyperactivity Disorder. Arch Clin Neuropsychol 14:373-387. CrossRef Medline

Edeline JM, Manunta Y, Hennevin E (2011) Induction of selective plasticity in the frequency tuning of auditory cortex and auditory thalamus neurons by locus coeruleus stimulation. Hear Res 274:75-84. CrossRef Medline

Elie JE, Theunissen FE (2015) Meaning in the avian auditory cortex: neural representation of communication calls. Eur J Neurosci 41:546-567. CrossRef Medline

Escanilla O, Arrellanos A, Karnow A, Ennis M, Linster C (2010) Noradrenergic modulation of behavioral odor detection and discrimination thresholds in the olfactory bulb. Eur J Neurosci 32:458-468. CrossRef Medline

Foote SL, Freedman R, Oliver AP (1975) Effects of putative neurotransmitters on neuronal activity in monkey auditory cortex. Brain Res 86:229242. CrossRef Medline

Hasselmo ME, Linster C, Patil M, Ma D, Cekic M (1997) Noradrenergic suppression of synaptic transmission may influence cortical signal-tonoise ratio. J Neurophysiol 77:3326-3339. Medline

Hurley LM, Devilbiss DM, Waterhouse BD (2004) A matter of focus: monoaminergic modulation of stimulus coding in mammalian sensory networks. Curr Opin Neurobiol 14:488-495. CrossRef Medline

Ikeda M, Rensel MA, Schlinger BA, Remage-Healey L (2014) In vivo detection of fluctuating brain steroid levels in zebra finches. Cold Spring Harbor Protoc 2014:1267-1272. CrossRef Medline

Jeong JK, Terleph TA, Burrows K, Tremere LA, Pinaud R (2011) Expression and rapid experience-dependent regulation of type-A GABAergic receptors in the songbird auditory forebrain. Dev Neurobiol 71:803-817. CrossRef Medline

Kasamatsu T, Pettigrew JD, Ary M (1979) Restoration of visual cortical plasticity by local microperfusion of norepinephrine. J Comp Neurol 185: 163-181. CrossRef Medline

Lynch KS, Ball GF (2008) Noradrenergic deficits alter processing of com- munication signals in female songbirds. Brain Behav Evol 72:207-214. CrossRef Medline

Lynch KS, Diekamp B, Ball GF (2012) Colocalization of immediate early genes in catecholamine cells after song exposure in female zebra finches (Taeniopygia guttata). Brain Behav Evol 79:252-260. CrossRef Medline

Manunta Y, Edeline JM (1997) Effects of noradrenaline on frequency tuning of rat auditory cortex neurons. Eur J Neurosci 9:833-847. CrossRef Medline

Manunta Y, Edeline JM (1999) Effects of noradrenaline on frequency tuning of auditory cortex neurons during wakefulness and slow-wave sleep. Eur J Neurosci 11:2134-2150. CrossRef Medline

Manunta Y, Edeline JM (2004) Noradrenergic induction of selective plasticity in the frequency tuning of auditory cortex neurons. J Neurophysiol 92:1445-1463. CrossRef Medline

Matragrano LL, Sanford SE, Salvante KG, Sockman KW, Maney DL (2011) Estradiol-dependent catecholaminergic innervation of auditory areas in a seasonally breeding songbird. Eur J Neurosci 34:416-425. CrossRef Medline

Matragrano LL, Beaulieu M, Phillip JO, Rae AI, Sanford SE, Sockman KW, Maney DL (2012) Rapid effects of hearing song on catecholaminergic activity in the songbird auditory pathway. PLoS One 7:e39388. CrossRef Medline

Nai Q, Dong HW, Hayar A, Linster C, Ennis M (2009) Noradrenergic regulation of GABAergic inhibition of main olfactory bulb mitral cells varies as a function of concentration and receptor subtype. J Neurophysiol 101: 2472-2484. CrossRef Medline

Newport DJ, NemeroffCB (2000) Neurobiology of posttraumatic stress disorder. Curr Opin Neurobiol 10:211-218. CrossRef Medline

Pawlisch BA, Stevenson SA, Riters LV (2011) $\alpha_{1}$-Noradrenegic receptor antagonism disrupts female songbird responses to male song. Neurosci Lett 496:20-24. CrossRef Medline

Peterson RS, Yarram L, Schlinger BA, Saldanha CJ (2005) Aromatase is presynaptic and sexually dimorphic in the adult zebra finch brain. Proc Biol Sci 272:2089-2096. CrossRef Medline

Pinaud R, Mello CV (2007) GABA immunoreactivity in auditory and song control brain areas of zebra finches. J Chem Neuroanat 34:1-21. CrossRef Medline

Pinaud R, Terleph TA, Tremere LA, Phan ML, Dagostin AA, Leão RM, Mello CV, Vicario DS (2008) Inhibitory network interactions shape the auditory processing of natural communication signals in the songbird auditory forebrain. J Neurophysiol 100:441-455. CrossRef Medline

Poirier C, Van der Linden AM (2011) Spin echo BOLD fMRI on songbirds. Methods Mol Biol 771:569-576. CrossRef Medline

Rapin I, Dunn M (2003) Update on the language disorders of individuals on the autistic spectrum. Brain Dev 25:166-172. CrossRef Medline

Remage-Healey L, Joshi NR (2012) Changing neuroestrogens within the auditory forebrain rapidly transform stimulus selectivity in a downstream sensorimotor nucleus. J Neurosci 32:8231-8241. CrossRef Medline

Remage-Healey L, Maidment NT, Schlinger BA (2008) Forebrain steroid levels fluctuate rapidly during social interactions. Nat Neurosci 11:13271334. CrossRef Medline

Remage-Healey L, Coleman MJ, Oyama RK, Schlinger BA (2010) Brain estrogens rapidly strengthen auditory encoding and guide song preference in a songbird. Proc Natl Acad Sci U S A 107:3852-3857. CrossRef Medline

Remage-Healey L, Dong SM, Chao A, Schlinger BA (2012) Sex-specific, rapid neuroestrogen fluctuations and neurophysiological actions in the songbird auditory forebrain. J Neurophysiol 107:1621-1631. CrossRef Medline

Robbins TW, Arnsten AF (2009) The neuropsychopharmacology of frontoexecutive function: monoaminergic modulation. Annu Rev Neurosci 32: 267-287. CrossRef Medline

Ruffolo RR Jr, Waddell JE (1982) Receptor interactions of imidazolines: alpha-adrenoceptors of rat and rabbit aortae differentiated by relative potencies, affinities and efficacies of imidazoline agonists. Br J Pharmacol 77:169-176. CrossRef Medline

Saldanha CJ, Tuerk MJ, Kim YH, Fernandes AO, Arnold AP, Schlinger BA (2000) Distribution and regulation of telencephalic aromatase expression in the zebra finch revealed with a specific antibody. J Comp Neurol 423:619-630. CrossRef Medline

Salgado H, García-Oscos F, Dinh L, Atzori M (2011a) Dynamic modulation of short-term synaptic plasticity in the auditory cortex: the role of norepinephrine. Hear Res 271:26-36. CrossRef Medline 
Salgado H, Garcia-Oscos F, Patel A, Martinolich L, Nichols JA, Dinh L, Roychowdhury S, Tseng KY, Atzori M (2011b) Layer-specific noradrenergic modulation of inhibition in cortical layer II/III. Cereb Cortex 21:212-221. CrossRef Medline

Salgado H, Garcia-Oscos F, Martinolich L, Hall S, Restom R, Tseng KY, Atzori M (2012) Pre- and postsynaptic effects of norepinephrine on gammaaminobutyric acid-mediated synaptic transmission in layer $2 / 3$ of the rat auditory cortex. Synapse 66:20-28. CrossRef Medline

Sato H, Fox K, Daw NW (1989) Effect of electrical stimulation of locus coeruleus on the activity of neurons in the cat visual cortex. J Neurophysiol 62:946-958. Medline

Schneider DM, Woolley SM (2013) Sparse and background-invariant coding of vocalizations in auditory scenes. Neuron 79:141-152. CrossRef Medline

Shepard KN, Liles LC, Weinshenker D, Liu RC (2015) Norepinephrine is necessary for experience-dependent plasticity in the developing mouse auditory cortex. J Neurosci 35:2432-2437. CrossRef Medline

Sizemore M, Perkel DJ (2008) Noradrenergic and GABA B receptor activation differentially modulate inputs to the premotor nucleus RA in zebra finches. J Neurophysiol 100:8-18. CrossRef Medline

Sockman KW, Salvante KG (2008) The integration of song environment by catecholaminergic systems innervating the auditory telencephalon of adult female European starlings. Dev Neurobiol 68:656-668. CrossRef Medline

Sweet RA, Henteleff RA, Zhang W, Sampson AR, Lewis DA (2009) Reduced dendritic spine density in auditory cortex of subjects with schizophrenia. Neuropsychopharmacology 34:374-389. CrossRef Medline

Tillman GD (2010) Estradiol levels during the menstrual cycle differentially affect latencies to right and left hemispheres during dichotic listening: an ERP study. Psychoneuroendocrinology 35:249-261. CrossRef Medline

Tremere LA, Pinaud R (2011) Brain-generated estradiol drives long-term optimization of auditory coding to enhance the discrimination of communication signals. J Neurosci 31:3271-3289. CrossRef Medline

Tremere LA, Jeong JK, Pinaud R (2009) Estradiol shapes auditory processing in the adult brain by regulating inhibitory transmission and plasticityassociated gene expression. J Neurosci 29:5949-5963. CrossRef Medline

Vahaba DM, Lacey WH, Tomaszycki ML (2013) DSP-4, a noradrenergic neurotoxin, produces sex-specific effects on pairing and courtship behavior in zebra finches. Behav Brain Res 252:164-175. CrossRef Medline

Vazey EM, Aston-Jones G (2014) Designer receptor manipulations reveal a role of the locus coeruleus noradrenergic system in isoflurane general anesthesia. Proc Natl Acad Sci U S A 111:3859-3864. CrossRef Medline

Velho TA, Lu K, Ribeiro S, Pinaud R, Vicario D, Mello CV (2012) Noradrenergic control of gene expression and long-term neuronal adaptation evoked by learned vocalizations in songbirds. PLoS One 7:e36276. CrossRef Medline

Wade J, Schlinger BA, Hodges L, Arnold AP (1994) Fadrozole: a potent and specific inhibitor of aromatase in the zebra finch brain. Gen Comp Endocrinol 94:53-61. CrossRef Medline

Wang Y, Brzozowska-Prechtl A, Karten HJ (2010) Laminar and columnar auditory cortex in avian brain. Proc Natl Acad Sci U S A 107:1267612681. CrossRef Medline

Woolley SM, Rubel EW (2002) Vocal memory and learning in adult Bengalese Finches with regenerated hair cells. J Neurosci 22:7774-7787. Medline 